\title{
Simulation of a Series Double Cavity Buffer on the Landing Gear
}

\author{
Xu Zhang ${ }^{1, a}$, Da Song ${ }^{1, b}$, Wenxiu Shang ${ }^{1, c}$, Lixun Zhang ${ }^{1, d}$, \\ Kunlun $\mathrm{Wu}^{1, \mathrm{e}}$, Yiwen Zhang ${ }^{1, \mathrm{f}}$, Qihe Zhang $^{1, \mathrm{~g}}$ \\ ${ }^{1}$ Harbin Engineering University, Harbin 150001, P. R. China \\ azhangxu@hrbeu.edu.cn, bsongda@hrbeu.edu.cn, c'shangwenxiu@hrbeu.edu.cn, 'zhanglixun@hrbeu.edu.cn, \\ ewukunlun@hrbeu.edu.cn, zhangyiwen@hrbeu.edu.cn and '7hangqihe@hrbeu.edu.cn
}

\begin{abstract}
Keywords: landing gear of helicopter; series double cavity buffer; simulation; analysis
Abstract. Adopting high performance buffer is the foundation of the landing gear on the helicopter. Based on established models on Adams/Aircraft, a novel type of series double cavity buffer on the landing gear is investigated by dynamic simulation. Corresponding simulation and analysis are achieved, which is helpful for farther structure optimization. It is shown that compared with single cavity buffer, the series double cavity buffer can reduce effectively the acceleration, vertical force and tire force of the landing gear. Under the same condition, vertical force and tire force of the landing gear increase with the initial pressure increase of the high pressure grade buffer in the series double cavity buffer.
\end{abstract}

\section{Introduction}

At present, landing gear buffers with the oil and gas mixed are applied widely in the helicopters and aircrafts [1]. Although they have different structures, same basic principle is adopted by the internal energy change and energy storage with the volume change of gas, squeezing liquid to flow through the damping oil hole for energy dissipation to make dynamic energy dissipated or absorbed [2]. A buffer with superior performance can reduce greatly the vibration of the helicopter during its landing. Apparently, high performance buffer is the foundation of the landing gear on the helicopter [3]. So as to increase the stability and safety of the helicopter landing, a novel type of series double cavity buffer on the landing gear is put forward, with the advantages of simple structure, fine property of energy absorption and low precision requirements.

\section{The structure and principle of series double cavity buffer}

As shown in Fig.1, the whole outer frame of series double cavity buffer is composed of low end of buffer pillar 1, middle part of buffer pillar 4, upper end of buffer pillar 7 and compensation part of buffer pillar 8 . The amplificatory structure of damping valve 11 is shown in Fig.2. In the valve body 23, piston plate 22 and retainer nut 25 work together as a valve for damping, and the damping valve 11 with bronze piston 13 is fixed on the top of the lower end of buffer pillar 1 . The damping valve body 23 is fixed on the top of the middle part of buffer pillar 4 . The upper end of buffer pillar 7 is connected with compensation part of buffer pillar 8 by using thread 10 .

When internal pressure between the lower end of buffer pillar 1 and the middle part of buffer pillar 4 is greater than the gas pressure in low pressure gas cavity 2, the low pressure grade buffer is compressed and the normal working condition will start. At this time, damping valve 11 in the piston plate 22 under pressure difference will separate with valve body 23, pressure oil flows rapidly through damping oil hole for positive stroke 21, damping oil hole for reverse stroke 20 and oil hole 24, the damping valve 11 produces hydraulic damping and heat energy consumption. Then the piston plate 22 in the low pressure grade buffer is pushed to move down, and compress the gas in the low pressure gas cavity 2, the gas pressure and air spring force increase, so the internal energy of gas increases with dissipated energy stored. 


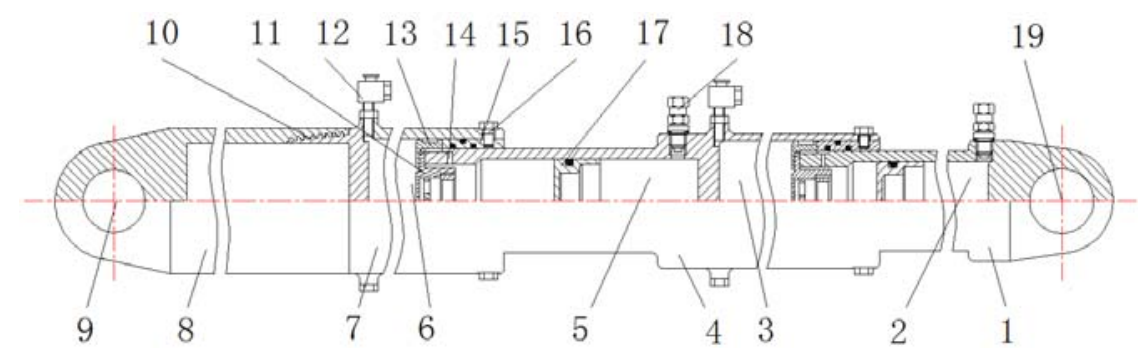

Fig.1 Series double cavity buffer with damping valve

1.Low end of buffer pillar 2.Low pressure gas cavity 3.Low pressure oil cavity 4.Middle part of buffer pillar 5.High pressure gas cavity 6.High pressure oil cavity 7.Upper end of buffer pillar 8.Compensation part of buffer pillar 9.Upper hinge hole 10.Thread 11.Damping valve 12.Oil injection valve 13.Bronze piston 14.Oil hole 15. Seal sleeve 16.Screw 17.Floating piston 18.Charge valve 19.Lower hinge hole

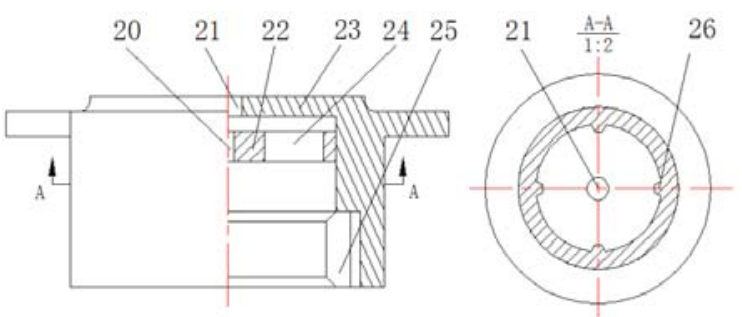

Fig.2 The structure of damping valve

20. Damping oil hole for reverse stroke 21.Damping oil hole for positive stroke 22. Piston plate 23. Valve body 24.Oil hole 25. Retainer nut 26. Piston plate guide

\section{Virtual prototype model establishment of series double cavity buffer}

By means of ADAMS/Aircraft software, the virtual prototype model of the series double cavity buffer is established and assembled to the landing gear. Parameter input modules for virtual prototype model are shown in Fig.3. Input module for air spring is given in Fig.3 (a). Input module for oil damper is given in Fig.3 (b).

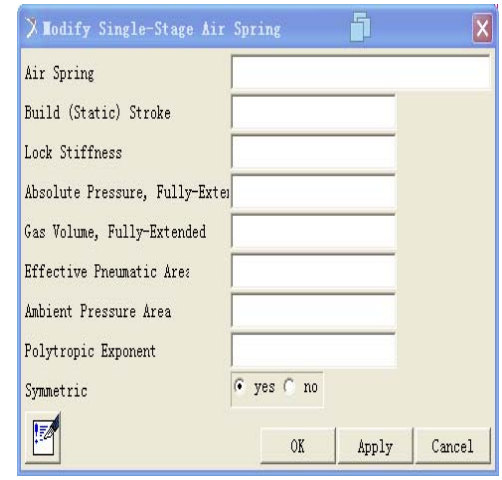

(a)

(a) Input module for air spring

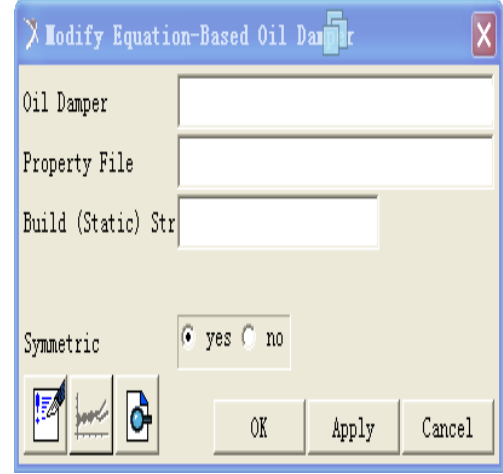

(b)

(b) Input module for oil damper

Fig.3 Parameter input modules for virtual prototype model

\section{Simulation and Analysis}

Drop test and initial conditions. Drop test is an independent dynamic test for landing gear on the helicopter. It is not only an effective research method for studying the characteristics of the landing gear and optimization methods of the buffer parameters, but a best way to check the performance of landing gear [4]. The parameters of series double cavity buffer on the landing gear is shown in table 1, which are employed in following simulation of drop test as initial conditions. 
Table 1 Parameters of series double cavity buffer on the landing gear

\begin{tabular}{c|c|c}
\hline Parameters & \multicolumn{2}{|c}{ Series double cavity buffer } \\
\hline Equivalent mass $m_{e}(\mathrm{Kg})$ & \multicolumn{2}{|c}{5250} \\
\hline Pressure stage & Low pressure stage & High pressure stage \\
\hline Piston radius $R(\mathrm{~mm})$ & 33.8 & 37 \\
\hline Maximum stroke $S_{\max }(\mathrm{mm})$ & 300 & 150 \\
\hline Equivalent area of oil hole for positive stroke $S\left(\times 10^{-5} \mathrm{~m}^{2}\right)$ & 3.77 & 6.94 \\
\hline Equivalent area of oil hole for reverse stroke $S_{1}\left(\times 10^{-5} \mathrm{~m}^{2}\right)$ & 1.88 & 3.47 \\
\hline Initial gas volume $V\left(\times 10^{-3} \mathrm{~m}^{3}\right)$ & 1.85 & 1.19 \\
\hline Initial gas pressure $P(\mathrm{MPa})$ & 2.2 & 8.0 \\
\hline
\end{tabular}

Simulation results. Landing gear with single cavity buffer and series double cavity buffer are all simulated for comparison. The condition is set as hard landing, speed is $6 \mathrm{~m} / \mathrm{s}$ with the same buffer parameters and the landing gear is the same.

Fig.4 indicates that the stroke of air compression spring with single cavity buffer is shorter than that with series double cavity buffer just in the drop time of start stage, but all almost the same in the posterior compression springback stage.

Fig. 5 indicates that the vertical force of the equivalent mass point versus total stroke, the landing gear with the series double cavity buffer has obvious advantages compared with that with single cavity buffer. The vertical force of the equivalent mass point with the series double cavity buffer is about $62 \%$ of the vertical force with single cavity buffer.

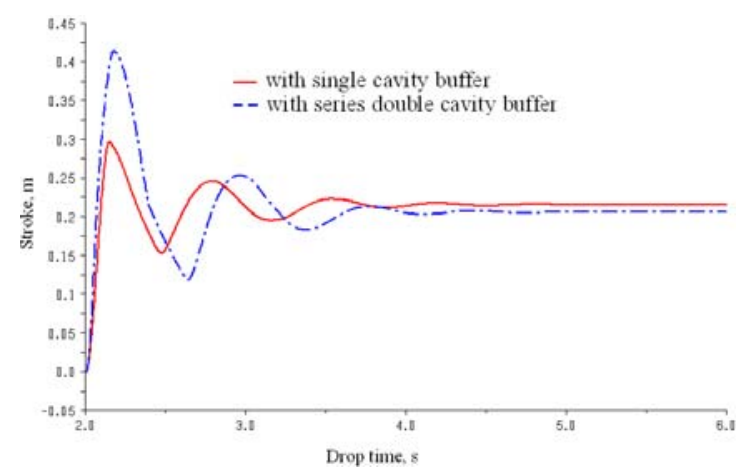

Fig.4 Stroke versus drop time

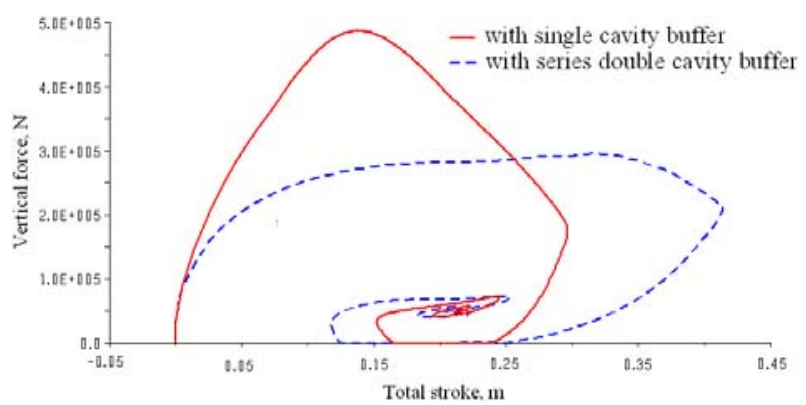

Fig.5 Vertical force versus total stroke

Analysis of high pressure grade parameters. Might as well, low pressure grade buffer parameters remain constant and the piston radius of high pressure grade buffer is fixed. Multiple sets of initial pressure are given below during simulation.

Fig.6 and Fig.7 indicate that under the same landing speed, vertical force and tire force of the landing gear increase with the initial pressure increase of the high pressure grade buffer.

In order to investigate further the impact of the buffer parameters of the high pressure grade buffer on the landing gear, the initial pressure 9MPa of the high pressure grade buffer is set, the piston radius $\mathrm{R}$ is reduced by $5 \%$ one by one, the buffer parameters are kept constant, drop velocity is $6 \mathrm{~m} / \mathrm{s}$. Based on above mentioned conditions, further simulated is achieved.

Fig.8 indicates that with the decrease of the high pressure piston radius, the total stroke of the low pressure grade buffer is almost the same as that of the start compression stroke. And the amplitude of the subsequent springback compression has apparent difference only when the high pressure piston radius is reduced to $0.85 \mathrm{R}$. The stroke and vibration of the high pressure grade buffer increase slowly with the decrease of the piston radius before piston radius reduces to 0.85R. Fig.9 indicates that during the range of $0.85 R \sim R$, piston radius $R$ has little effects on tire force actually. 


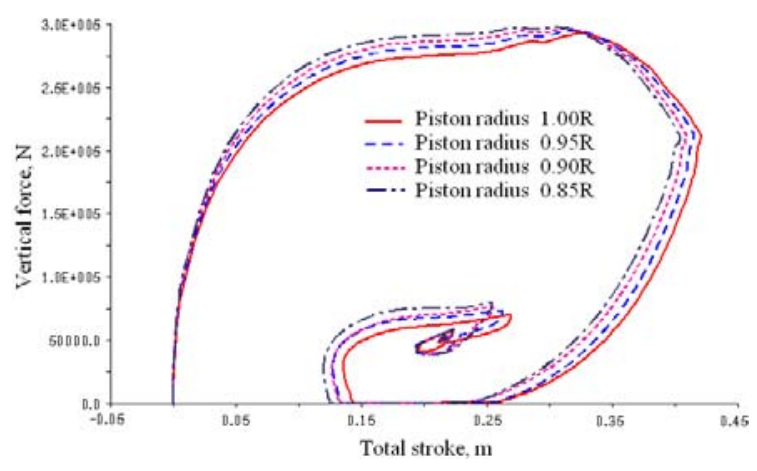

Fig.6 Vertical force versus total stroke

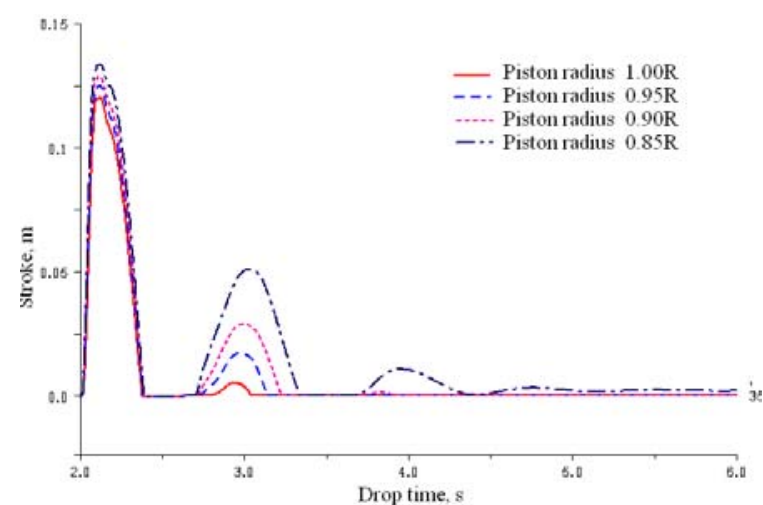

Fig.8 Stroke of high pressure grade buffer versus drop time

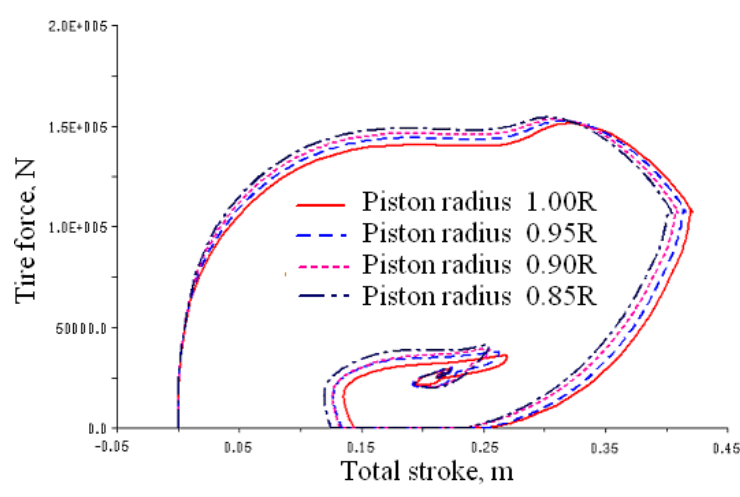

Fig.7 Tire force versus total stroke

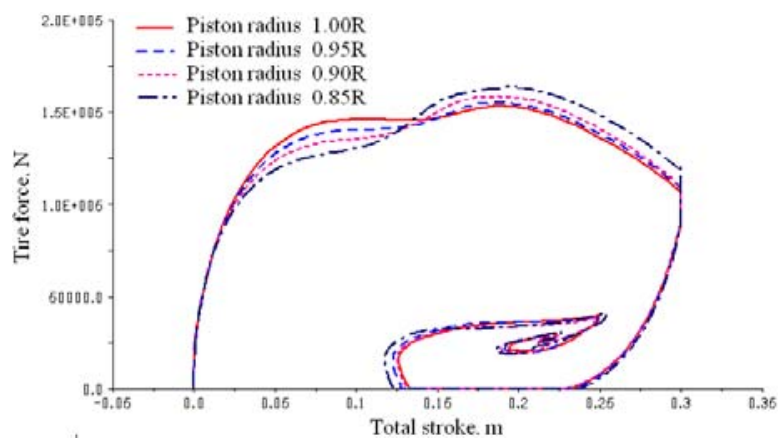

Fig.9 Tire force versus total stroke

\section{Conclusions}

Based on a novel type of series double cavity buffer on the landing gear, simulation and analysis are carried out. It is shown that compared with single cavity buffer, the series double cavity buffer can reduce more effectively dynamic acceleration, vertical force and tire force of the landing gear. Under the same condition, vertical force and tire force increase with the initial pressure increase of the high pressure grade buffer in the series double cavity buffer. During the range of $0.85 \mathrm{R} \sim \mathrm{R}$, piston radius has little effects on tire force.

\section{Acknowledgement}

We gratefully acknowledge the help of Dr. Xiaodong Xing. This thesis is supported by NSFC, China (51179040).

\section{References}

[1] Basset P.M, Brocard M. A Fenestron Model for Improving the Helicopter Yaw Dynamics Flight Simulation [R]. 30th European Rotorcraft Forum, Marseilles. 2004(14)

[2] Xiao Jianqiu, Peng Gao. Plastic Limit Load Analysis of Buttress Casing Thread Connection [J]. Oil Field Machinery. 2008, 9(3):53-56. (In Chinese)

[3] Liu Chongren, Chen Zhenxing. Technology of Dynamic Analysis for Aircraft Landing Gear [J]. Popular Science and Technology. 2013, 16(3): 80-82. (In Chinese)

[4] Choi .T, Werley N.M. Vibration Control of a Landing Gear System Featuring Electrorheological/Magnetorheological Fluids. Journal of Aircraft. 2003, 40(3):432-439 